\title{
Water Deficiency Detection of Hevea brasiliensis Clones by Laser Induced Fluorescence
}

\author{
Emma Georgina ZORO-DIAMA ${ }^{1}$, Adama Penetjiligue SORO ${ }^{1}$, Kedro Sidiki DIOMANDE ${ }^{2}$, Kouadio DIAN², \\ Amara KAMATE ${ }^{1}$ \& Adjo Viviane ADOHI-KROU ${ }^{1}$ \\ ${ }^{1}$ Cristallography and Molecular Physics Laboratory, Félix Houphouët-Boigny University, Côte d'Ivoire \\ ${ }^{2}$ Centre National de Recherche Agronomique (CNRA), Côte d'Ivoire \\ Correspondence: Emma Georgina ZORO-DIAMA, Cristallography and Molecular Physics Laboratory, Félix \\ Houphouët-Boigny University, Côte d'Ivoire. E-mail: gina_zoro@yahoo.fr
}

Received: July 26, 2017

Accepted: August 10, 2017

Online Published: August 23, 2017

doi:10.5539/apr.v9n5p36

URL: https://doi.org/10.5539/apr.v9n5p36

\begin{abstract}
Water is the key nutritional element for the optimal development of plants. A water deficiency leads to lower crop productivity. As the health status of a plant influences the photosynthesis process, a photosynthetic diagnosis of a plant can be carried by laser induced chlorophyll fluorescence, a reliable and fast method that is non-destructive to the sample. In this study, we show that it is possible to detect the water deficiency of rubber tree hevea brasiliensis from the chlorophyll fluorescence ratio. The fluorescence ratio used in this study is called the effective ratio and it corresponds to the both fluorescence peaks ratio. We noticed that the water deficient plants fluorescence ratios were higher than those of normally watered plants. Moreover, the stressed plants' ratios are greater than a threshold value which depends on the duration of water deprivation application.
\end{abstract}

Keywords: hevea brasiliensis, water deficiency, hydric stress, chlorophyll fluorescence

\section{Introduction}

Rubber tree is a perennial plant mainly cultivated for the sap extracted from its bark. Indeed, $90 \%$ of the dry weight of this latex is made of rubber (Obouayeba et al., 2006). Rubber is used as a raw material in the biomedical, pharmaceutical and pneumatic industries (Okoma, Dian, Allou, \& Sangare, 2009). Rubber tree culture which began in 1950 in Côte d'Ivoire, is steadily increasing. Currently, Côte d'Ivoire is the first african country producer of natural rubber and ranks seventh one in the world, with a production of 317000 tonnes in 2015 (World bank, 2016). At the end of the rubber exploitation period, its wood can also be used as softwood lumber or firewood. Furthermore, this perennial plant can be used for reforestation, given the structure of its foliage. So, besides being a source of income for rubber producers, this plant can also help to reforest arid zones in order to reduce desertification and global warming.

The planting of rubber trees in low rainfall areas requires the selection of plants that are tolerant to water deficiency. In agronomy, the usual methods require years of study in real situation (Clément-Demange, Rivano, Nicolas, Gnagne, \& Legnaté, 1995; Da Costa, De Resende, De Araujo, De Souza Gonçalves, \& Higa , 2000). The use of physical methods, especially laser induced chlorophyll fluorescence is a faster, more reliable and non destructive alternative to plants.

Indeed, the fluorescence emission is directly related to the photosynthesis process (Papageorgiou, \& Govindjee, 2004; Stirbet, \& Govindjee, 2011; Wim, \& Andrej, 2013) which itself reflects the plant health. Thus, the fluorescence spectrum study makes it possible to detect any stress undergone by the plant (Méthy, Olioso, \& Trabaud, 1994; Bourrié, 2007) at the leaf scale or canopy scale.

In this work, we aim to detect the hydric deficiency of hevea brasiliensis clones by the laser induced chlorophyll fluorescence technique. 


\section{Material}

\subsection{Experimental Material}

For this experiment, data were collected in vivo and in situ using an USB4000 - type FL spectrometer. This device can record plant chlorophyll fluorescence spectra and reflectance spectra whose wavelengths range is from $360 \mathrm{~nm}$ to $1000 \mathrm{~nm}$ in steps of $0.22 \mathrm{~nm}$.

The samples were excited by a LED emitting at $450 \mathrm{~nm}$ through a bifurcated optical fiber. The acquisition, storage and processing of the collected spectral data were conducted using a laptop. The Figure 1 shows the experimental setup.

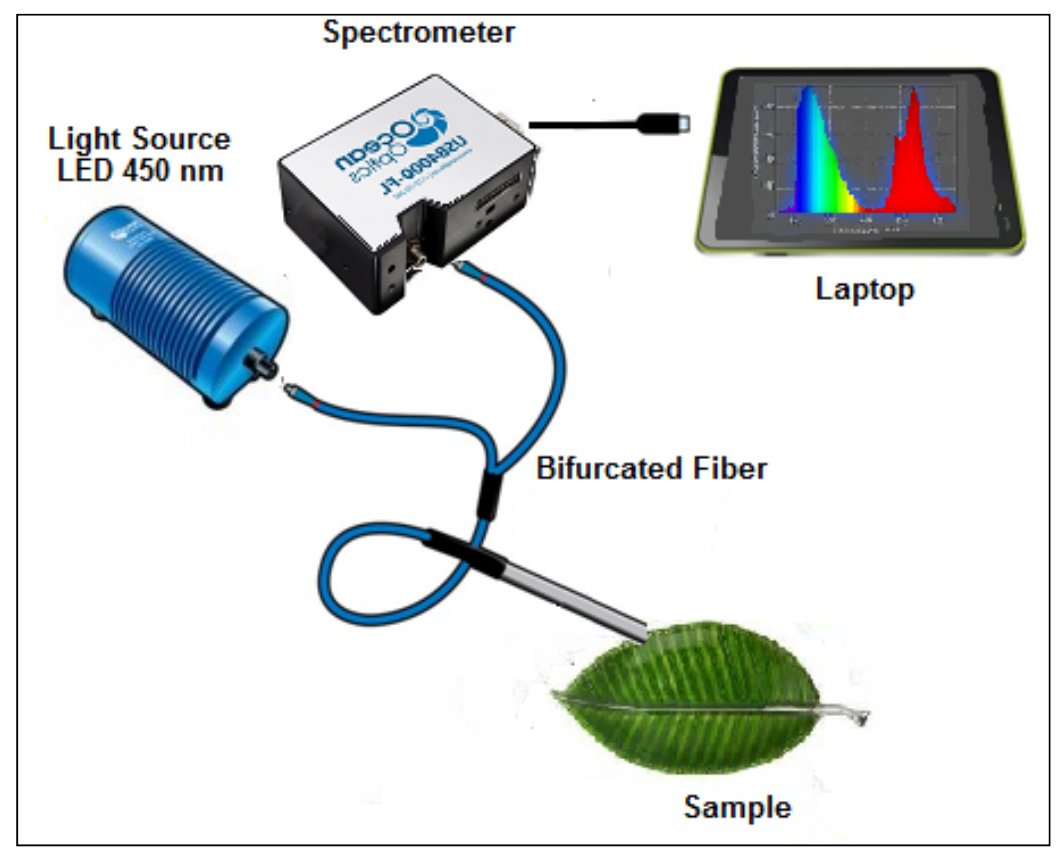

Figure 1. Experimental setup for laser induced chlorophyll fluorescence

\subsection{Vegetal Material}

We studied five hevea brasiliensis clones, named $\mathrm{C} 2, \mathrm{C} 5, \mathrm{C} 7, \mathrm{C} 9$ and $\mathrm{C} 10$. They were provided by the Centre National de Recherche Agronomique (CNRA) in Côte d'Ivoire. Theses clones are the most used in Côte d'Ivoire because they produce more latex with a good quality.

\section{Methods}

\subsection{Water Stress Induction}

Hevea brasiliensis seeds were germinated in plastic bags with three replications. These seeds were watered every two (02) days. The seedlings of the five clones that grew after two months, were transplanted into 5 liters buckets. These buckets were previously filled with a mixture of soil containing all mineral elements necessary for the plant efficient development. Then, these buckets were randomly arranged under a greenhouse (see figure 2), as we did not want to be dependent on the rainfall. In the greenhouse, mean values of temperature and humidity were respectively $30^{\circ} \mathrm{C}$ and $78 \%$. We continue watering the plants. But from the fourth month, the rubber plants were divided into two categories :

- $\quad$ the control plants which are still normally watered (Normally Watered Plants or NWP);

- $\quad$ and the stressed plants which are not watered (Water Deficient Plants or NDP).

From this date and twice a week, the fluorescence spectra of every plant were recorded. This operation took place between 09:00 am and 01:00 pm. Then, we performed four sets of measurements in two weeks, until the plants were dry. So, the measurements were carried out respectively 04, 08, 11 and 15 Days after application of the water Stress (DAS). 


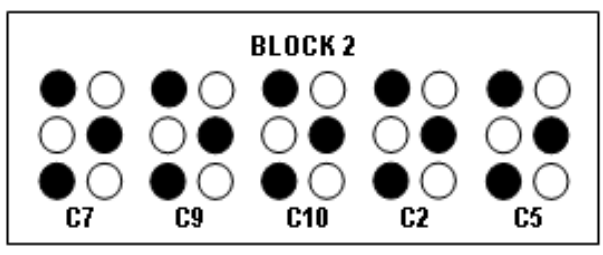

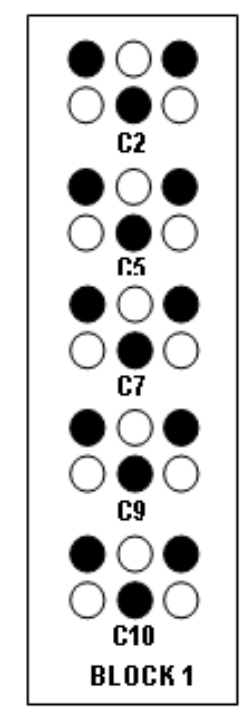

Normally watered plant (NWP)

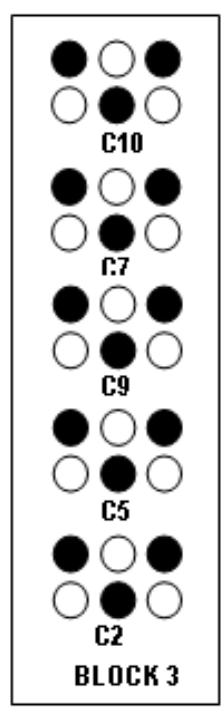

Water defident plant (WDP)

Figure 2. Water stress study planting plan

\subsection{Data Processing}

The systematic ratio, computed from intensities of the fluorescence peaks at $690 \mathrm{~nm}$ and $740 \mathrm{~nm}$ is widely and successfully used in plant stress detection (Tremblay, Wang, \& Cerovic, 2012; Soro et al., 2016). The effective ratio corresponds to the ratio of both fluorescence peaks. The first ratio is widely used unlike the second one. However, for a plant, the peaks may not be at $690 \mathrm{~nm}$ and $740 \mathrm{~nm}$. The effective ratio reflects what really happens in the plant. It is therefore more suitable to study plants exposed to different stresses. So, in this work, we will compute effective peaks ratios to evaluate the resistance to water deficiency of rubber plants.

During the measures at leaf scale, the hydric deficiency applied to the plant in the same block, was characterized from the averaged fluorescence spectra. The mean spectrum per block, for a clone at a given stress level, is the result of fifteen (15) measurements. Indeed, it is recommended to use the mean value of the fluorescence ratio for many measurements to have reliable results instead of one single measurement (Fedotov, Bullo, Belov, \& Gorodnichev, 2016).

We noticed that for the same applied stress level, there is no significant difference between the measurements performed on the blocks. We then worked with the average values of the effective fluorescence ratios computed on the three blocks, for the same given deficiency level.

For all the recorded spectra, the digital data are converted to ASCII files and then imported into the MATLAB software to compute the ratios of intensities for the two effective chlorophyll fluorescence peaks.

The various graphics were edited with the software ORIGINPro 8.

\section{Results and discussion}

\subsection{Temporal Evolution of $R$ for Five Clones after Stopping Watering}

The figure 3 shows for each clone, the effective fluorescence intensities ratio $R=F_{1} / F_{2}\left(F_{1}\right.$ and $F_{2}$ are the fluorescence intensities of the first and second peaks respectively) as a function of the number of days after water stress application. For each examined clones, we observe that the fluorescence ratio values of stressed plants are higher than those of the control ones. 


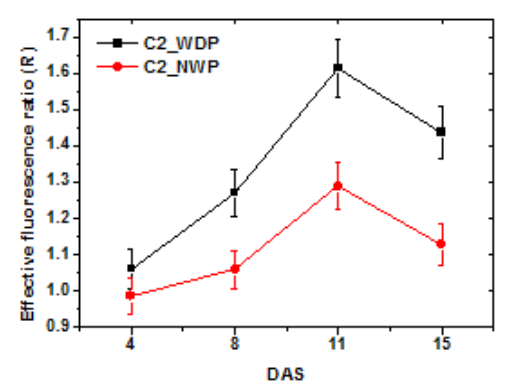

(a)

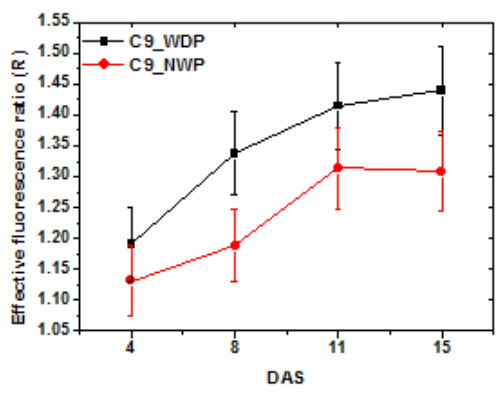

(d)

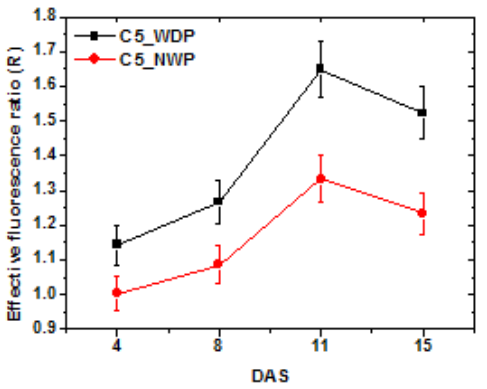

(b)

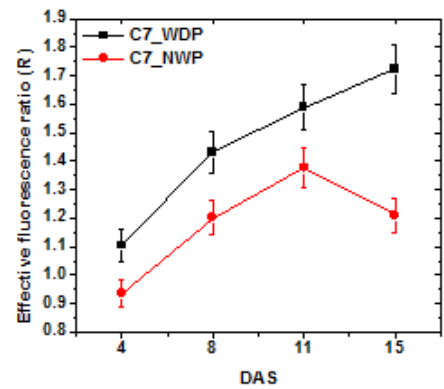

(c)

Figure 3. Temporal evolution of the effective ratio $\mathrm{R}$ after hydric stress application. (NWP $=$ Normally Watered Plants ; WDP $=$ Water Deficient Plants)

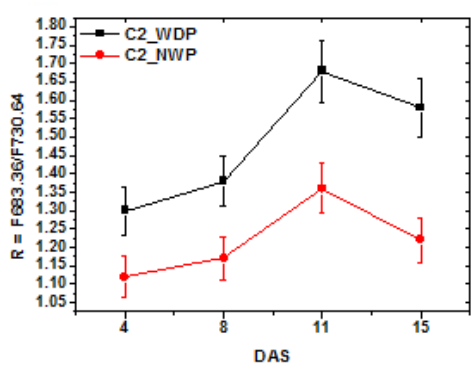

(a)

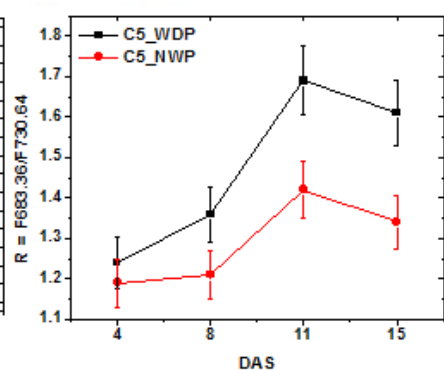

(b)

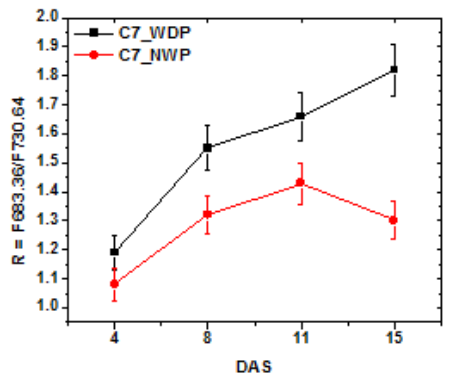

(c)

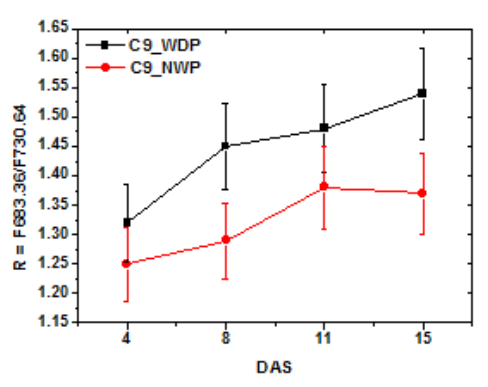

(d)

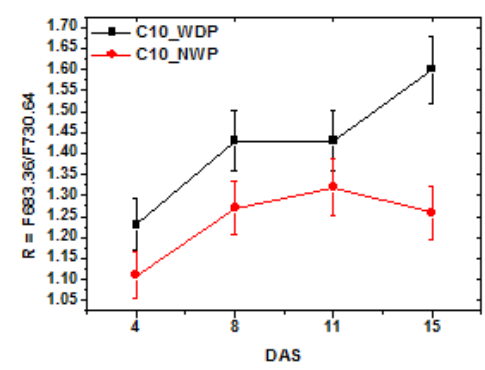

(e)

Figure 4. Temporal evolution of the fluorescence ratio for both peaks $\lambda_{1}=683.36 \mathrm{~nm}$ and $\lambda_{2}=730.64 \mathrm{~nm}$.

Moreover, for the $\mathrm{C} 2$ and $\mathrm{C} 5$ clones (graphs $3 \mathrm{a}$ and $3 \mathrm{~b}$ ), the WDP and NWP curves have similar characteristics. But, for the $\mathrm{C} 7, \mathrm{C} 9$ and $\mathrm{C} 10$ clones (graphs $3 \mathrm{c}, 3 \mathrm{~d}$ and $3 \mathrm{e}$ ), from the $11^{\text {th }}$ day after stress application, the R values continued increasing for WDP whereas theses values decreased for NWP. This observation highlights the difference in the hydric stress tolerance of rubber plants. Since the water deficient plants of C2 and C5 clones display the same behavior as the control plants, we can say that these families (C2 and C5) are tolerant to water deprivation.

These observations are also showed on the temporal evolution curves of $\mathrm{R}$ obtained for the mean values of fluorescence peaks positions (see figure 4). The found average wavelengths are: $\lambda_{1}=683.36 \mathrm{~nm}$ and $\lambda_{2}=730.64$ 
$\mathrm{nm}$. So for hevea brasiliensis plants, the fluorescence ratios measurements could be carried out at these wavelengths, instead of $690 \mathrm{~nm}$ and $740 \mathrm{~nm}$ values (systematic ratio) commonly used for the different clones under study.

\subsection{Comparison of $R$ values for each $D A S$}

Figure 5 shows the histograms of R values for the four DAS.
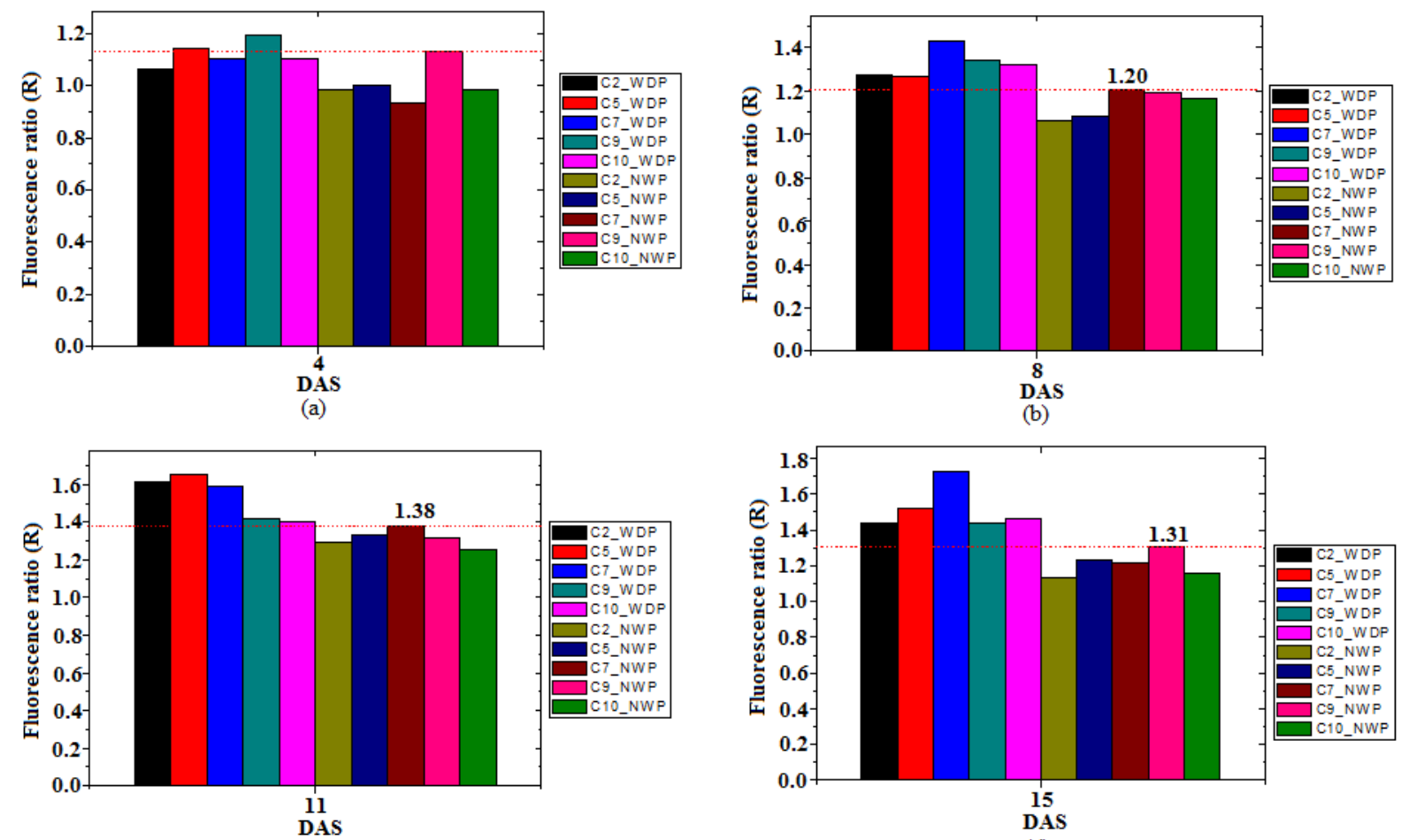

(b)

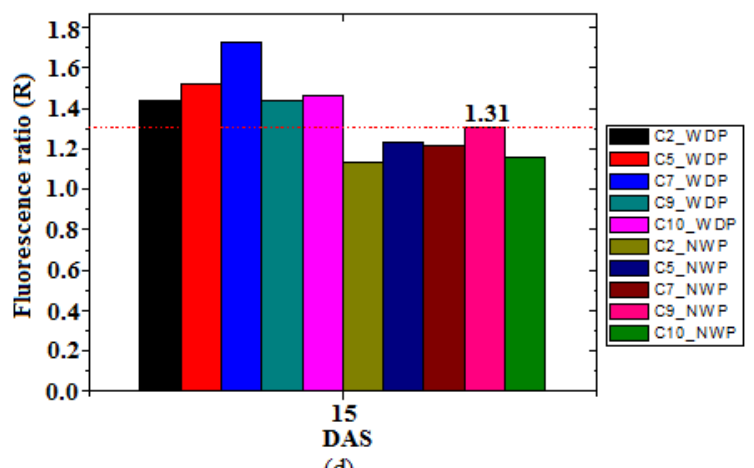

(c)

Figure 5. Histograms of R values for all DAS

At $8 \mathrm{DAS}$, we find that all stressed plants have a ration higher than 1.20 , while the control plants have a ratio lower than this value.

At 11DAS, the maximum value of ratio for control plants is equal to 1.38 . The stressed plants have a ratio greater than this value.

At 15DAS, the maximum value of ratio for control plants is equal to 1.31 . The stressed plants have a ratio greater than this value.

But, at 4DAS, no threshold value for the control plants can be found. The stress application time is not long enough for its effects to be perceptible.

Thus, we find that there is a maximum value for the fluorescence ratio of plants without water deprivation. The deficient plants have always a ratio higher than this value.

\section{Conclusion}

This study allowed to show that it is possible to detect the water deficiency of hevea brasiliensis plants from the ratio of both effective chlorophyll fluorescence peaks.

Indeed, stressed plants fluorescence ratio values are higher than those of control plants. Moreover, from 8DAS, all the stressed plants have a ratio greater than a threshold value while the control plants have a ratio lower than or equal to this threshold value. The threshold value is not a constant: it is equal to 1.20 at 8DAS, 1.38 at 11DAS and 1.31 at 15DAS. At 4DAS, the lack of water is not yet perceptible in most stressed plants.

Also, the $\mathrm{C} 2$ and $\mathrm{C} 5$ clones showed tolerance to water deprivation.

However, further experiments must be led to determine when, between 4DAS and 8DAS, the stress is really detectable for all clones. 


\section{Acknowledgements}

We thank the Centre National de Recherche Agronomique (CNRA) for their scientific collaboration.

\section{References}

Bourrié, B. (2007). La fluorescence chlorophyllienne comme outil de diagnostic, 8èmes Journées de la fertilisation raisonnée et de l'analyse de terre, GEMAS-COMIFER, Blois, 20-21 novembre, 11p. Retrieved from http://www.comifer.asso.fr/images/pdf/8emes_rencontres/15\%20-\%20expos $\% 20-\% 20 \% 201 \mathrm{a} \% 20$ fluorescen ce\%20chlorophyllienne\%20comme\%20outil\%20.pdf

Clément-Demange, A., Rivano F., Nicolas D., Gnagne M. Y., \& Legnaté H. (1995). Stratégies de sélection chez l'hévéa. In : Traitements statistiques des essais de sélection : stratégies d'amélioration des plantes pérennes. CIRAD-CP. Montpellier : CIRAD-CP, 227 - 242. (Colloques).

Da Costa, R. B., De Resende M. D. V., De Araujo A. J., De Souza Gonçalves P., \& Higa A. R. (2000). Selection and genetic gain in rubber tree (Hevea) populations using a mixed mating system. Genet. Mol. Biol., 23(3), 671-679. http://dx.doi.org/10.1590/S1415-47572000000300028

Fedotov, Y., Bullo, O., Belov, M., \& Gorodnichev, V. (2016). Experimental research of reliability of plant stress State detection by Laser-Induced Fluorescence Method. Int $J$ Optics, 1-6. http://dx.doi.org/10.1155/ 2016/4543094

Méthy, M., Olioso, A., \& Trabaud, L. (1994). Chlorophyll fluorescence as a tool for management of plant ressources. Remote Sensing of Environment, 47, 2-9. http://dx.doi.org/10.1016/0034-4257(94)90121-X.

Obouayeba, S., Gnagne Y. M., Wahounou P. J., Boko C., Sylla S., Kéli Z. J., \& Déa G. B. (2006). Bien cultiver l'hévéa en Côte d'Ivoire, fiche technique Centre National Recherche Agronomique, 4p. Retrieved from http://www.erails.net/images/cote-divoire/cnra/cnra/file/fiches\%20techniques/hevea.pdf

Okoma, K. M., Dian, K., Allou, D., \& Sangaré, A. (2009). Etude de la sensibilité des clones d'Hevea brasiliensis (Muell. Arg.) à l'encoche sèche. Sciences \& Nature, 6(1), 17-26.

Papageorgiou, G. C., \& Govindjee. (2004). Chlorophyll a fluorescence: A signature of photosynthesis. Advances in photosynthesis and respiration, 19. Springer, Dordrecht, 795p.

Soro, A. P., Zoro-Diama E. G., Diomandé K. S., Bany, G. E., Bibila Mayaya Bisseyou, Y., \& Adohi-Krou, A. V. (2016). Characterization of Water and Nitrogen Stress of Maize by Laser Induced Fluorescence, Applied Physics Research, 8(4), 64-72. http://dx.doi.org/10.5539/apr.v8n4p64

Stirbet, A., \& Govindjee. (2011). On the relation between the Kautsky effect (chlorophyll a fluorescence induction) and Photosystem II: Basics and applications of the OJIP fluorescence transient, Journal of Photochemistry and Photobiology B, 104(1-2), 236-257. http://dx.doi.org/10.1016/j.jphotobiol.2010.12.010

Tremblay, N., Wang, Z., \& Cerovic, Z. G. (2012). Sensing crop nitrogen status with fluorescence indicators- A review, Agronomy Sust Developm, 32(2), 451-464. http://dx.doi.org/10.1007/s13593-011-0041-1

Wim, V., \& Andrej, P. (2013). Chlorophyll $a$ fluorescence induction (Kautsky curve) in a Venus flytrap (Dionaea muscipula) leaf after mechanical trigger hair irritation. Journal of Plant Physiology, 170, 242-250. http://dx.doi.org/10.1016/j.jplph.2012.09.009.

World Bank. (2016). Commodity Market Outlook: Weak Growth in Emerging Economies and Commodity Markets, World Bank Quaterly Report, World Bank group, January 2016, 73p. Retrieved from https://openknowledge. worldbank.org/bitstream/handle/10986/23680/CMOJan2016FullReport.pdf

\section{Copyrights}

Copyright for this article is retained by the author(s), with first publication rights granted to the journal.

This is an open-access article distributed under the terms and conditions of the Creative Commons Attribution license (http://creativecommons.org/licenses/by/4.0/). 